\title{
Development of a Thornthwaite Moisture Index Map for Trinidad and Tobago
}

\author{
Damian V. A. Alexander ${ }^{1, *}$, Derek Anthony Gay ${ }^{1}$, and Kyung Ho Park ${ }^{1}$ \\ ${ }^{1}$ University of the West Indies, Department of Civil \& Environmental Engineering, St. Augustine, Trinidad and Tobago
}

\begin{abstract}
The Thornthwaite Moisture Index (TMI) has been traditionally used as a climatic index parameter to estimate annual moisture status of soils (deficit/surplus), primarily in the agricultural domain. Engineers have also adopted the TMI in efforts to estimate volume change potential in expansive clays, where seasonal (temporal) moisture changes can be correlated to soil matric suction and ultimately volume change via appropriate mechanistic models. In Trinidad and Tobago, approximately $60 \%$ of the islands are covered with over-consolidated clays of medium to high plasticity. When combined with extreme variations in moisture status, these plastic clays have exhibited high volume change potential. This paper investigates the spatial distribution of this climatic index for Trinidad and Tobago, intending to develop an index map for the islands. Within the post-colonial era in Trinidad and Tobago (1962 present), the availability of consistent climatic data is limited to just two recording stations within the islands. The Meteorological Services of Trinidad and Tobago (MET) manages both stations: Piarco, Trinidad and Crown Point, Tobago, where consistent data exists for 36 years $(1981 \sim 2018)$. These two points and their limited data timeframe cannot support the development of a spatial TMI map for the islands. This research addresses this shortcoming by collecting and analysing historical climatic data collected at 28 stations over Trinidad and Tobago over the British Colonial era $(1931 \sim 1964)$. These data are recorded in publications of the Land Capability Surveys of The Imperial College of Tropical Agriculture (ICTA). Data sets of monthly rainfall data from the historical and at present for the Piarco location showed strong statistical coherence, examined through a t-test. Having justified the historical data, TMI values are calculated at all locations. Using the calculated TMI values, a map was developed using the GIS software, Surfer, and interpolation method of Kriging. In Trinidad, the map indicates high TMI at the north-eastern side of the island, with a significant decrease going into the south-western side. Low TMI values are observed in the most western side of Trinidad indicating substantially long dry season period, during which the underlying expansive clay can experience significant shrinkage.
\end{abstract}

\section{Introduction}

Highly plastic clays have the potential to shrink and swell, depending on the available moisture at a specific location. Situations can occur where a highly expansive soil can be found in an extremely wet climate or an arid climate, although the overall volume change of the soil may be negligible due to a restriction of moisture variations. Thus, the understanding of our climate regime is essential to better understand the expansive potential of clays in their field conditions.

Thornthwaite [1] developed a climate index (TMI), in which climatic types for varying locations can be accessed by only requiring monthly rainfall, temperature and northing coordinate. TMI maps have been developed for countries, namely in the United States of America [2] and parts of Australia [3-4]. These TMI maps further assist in the research of the estimation of volume change potential in expansive soils, as well as climate change and pavement deterioration [5]. Fig. 1 shows the TMI relationship to equilibrium suction of soils [6] and Table 1 shows the TMI relationship with the depths of moisture change [7]. The depth of moisture changes increases significantly as the TMI values shift from highly positive to highly negative. These relationships assist in foundation designs on expansive soils and have been implemented into building codes.

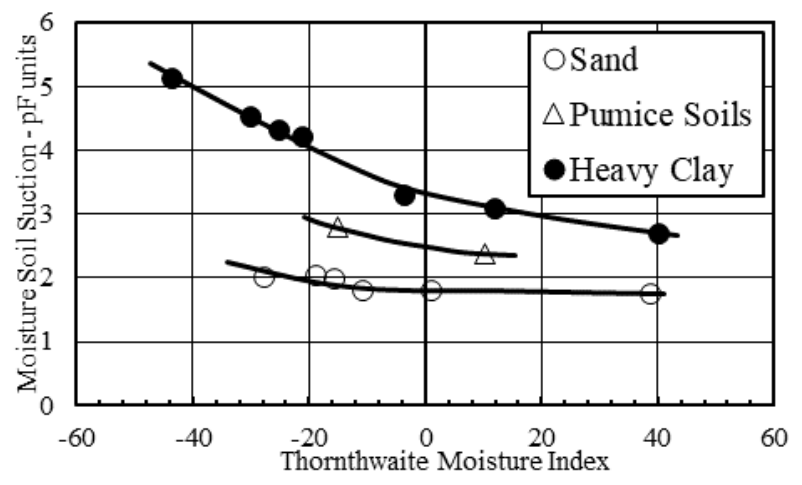

Fig. 1. TMI relationship to moisture soil suction. [6]

Corresponding author: damian.alexander@my.uwi.edu 
Table 1. Relationship of TMI to seasonal moisture depths. [7]

\begin{tabular}{|c|c|c|}
\hline TMI & Classification & $\begin{array}{c}\text { Depth of } \\
\text { Moisture } \\
\text { Change } \mathbf{H}_{\text {s }}\end{array}$ \\
\hline$>40$ & Wet Coastal/Alpine & $1.5 \mathrm{~m}$ \\
\hline 10 to 40 & Wet Temperate & $1.5-1.8 \mathrm{~m}$ \\
\hline-5 to 10 & Temperate & $1.8-2.3 \mathrm{~m}$ \\
\hline-25 to -5 & Dry Temperate & $2.3-3.0 \mathrm{~m}$ \\
\hline-40 to -25 & Semi-arid & $3.0-4.0 \mathrm{~m}$ \\
\hline$<-40$ & Arid & $>4.0 \mathrm{~m}$ \\
\hline
\end{tabular}

The design of post-tension slab foundations on expansive soils, uses the TMI values to estimate climateinduced settlement relating to edge moisture variations [8]. In the Australian Standard AS2870 for the design of slabs and footings, the TMI is used to predict surface movements [9].

In Trinidad and Tobago, there are no set building codes relating to expansive soils, and it is left to the discretion of an individual who may seek assistance from a competent engineer. Having $60 \%$ of the soils in Trinidad are covered with medium to highly plastic clays [10-11], significant moisture variations could influence the amount of volume change within these soils.

This paper investigates climate variations throughout Trinidad and Tobago and develops a TMI map, which can assist in the design of foundations on expansive clays.

\section{Methodology}

\subsection{Thornthwaite moisture index}

The TMI is a single number that classifies the climate regime of an area. It can be computed yearly or for an average number of years using equation 1 . The TMI is a combination of two main indices, the humidity index $\left(\mathrm{I}_{\mathrm{h}}\right)$ in equation 2 and aridity index $\left(\mathrm{I}_{\mathrm{a}}\right)$ in equation 3 . Computing these indices requires monthly Surplus (S), Deficits (D) and Potential Evapotranspiration (PE) at a particular location. Moisture deficits and surplus are calculated from the monthly precipitation and potential evapotranspiration through carrying out a monthly water balance. It is assumed that the field capacity at all sites is $100 \mathrm{~mm}$ by considering the mean value used by Russam and Coleman [6]. It is also assumed that the ground is fully saturated in December as the rainy season occurs from June to December. The PE is calculated from using the Northing location value and mean monthly temperature at the site in equation 4. The Adjustment (Adj.) factor is obtained through its correlation to the Northing and read off from Thornwaite's tables for corresponding values, with the use of the mean monthly temperature (t), the heat index (I), and correlation factor (a). Although Thornthwaite's determination of PE is simplistic, and there exist advanced methods, most empirical relationships to the TMI were developed using this method. For continuity, PE is calculated using Thornthwaite's method for the proposed TMI map.

$$
\begin{gathered}
\text { TMI }=I_{h}+\left(0.6 \times I_{a}\right) \\
I_{h}=100 \times\left(\frac{S}{P E}\right) \\
I_{a}=100 \times\left(\frac{D}{P E}\right) \\
\text { PE }(\mathrm{mm})=\left((\text { Adj.Factor }) \times 1.6\left(\frac{10 \mathrm{t}}{\mathrm{I}}\right)^{\mathrm{a}}\right) \times 10 \\
\text { where } \mathrm{I}=\sum_{\mathrm{i}=1}^{12}\left(\frac{\mathrm{t}_{\mathrm{i}}}{5}\right)^{1.514} \text { and } \\
\mathrm{a}=\left(\left(6.75 \times 10^{-7}\right) \times \mathrm{I}^{3}\right)-\left(\left(7.711 \times 10^{-5}\right) \times \mathrm{I}^{2}\right)+0.49239
\end{gathered}
$$

\subsection{Locations of historical rainfall data}

The historical rainfall data sets are taken from Brown and Bally book collection on Trinidad and Tobago Land Capability Surveys [12-15]. In total there are 28

\begin{tabular}{|c|c|c|c|}
\hline LOC & Name & Eastings & Northings \\
\hline 1 & Toco & -60.9497 & 10.83111 \\
\hline 2 & Valencia & -61.1906 & 10.69143 \\
\hline 3 & Arima & -61.2630 & 10.63853 \\
\hline 4 & Sangre Grande & -60.9991 & 10.83006 \\
\hline 5 & Diego Martin & -61.5552 & 10.74081 \\
\hline 6 & Santa Cruz & -61.4713 & 10.71146 \\
\hline 7 & POS & -61.5209 & 10.67072 \\
\hline 8 & St. Augustine & -61.3992 & 10.64372 \\
\hline 9 & Piarco & -61.3479 & 10.59266 \\
\hline 10 & Camdem & -61.4480 & 10.42209 \\
\hline 11 & La Vega & -61.3461 & 10.42300 \\
\hline 12 & Grosvenor & -61.1321 & 10.55188 \\
\hline 13 & Spring & -61.4163 & 10.41684 \\
\hline 14 & Mayaro & -61.0055 & 10.29486 \\
\hline 15 & Guyaguayare & -61.0609 & 10.13262 \\
\hline 16 & Moruga & -61.2801 & 10.08862 \\
\hline 17 & Barrackpore & -61.4492 & 10.16986 \\
\hline 18 & Siparia & -61.5445 & 10.17707 \\
\hline 19 & Point Fortin & -61.6597 & 10.17042 \\
\hline 20 & Cedros & -61.8058 & 10.11718 \\
\hline 21 & Friendship & -60.7941 & 11.14781 \\
\hline 22 & Gov. Farm & -60.7511 & 11.17578 \\
\hline 23 & Botanic Station & -60.7611 & 11.17007 \\
\hline 24 & Moriah & -60.7243 & 11.23202 \\
\hline 25 & Hillsborough & -60.6666 & 11.22807 \\
\hline 26 & Kendal & -60.6002 & 11.23367 \\
\hline 27 & King's Bay & -60.5563 & 11.26638 \\
\hline 28 & Hemitage & -60.5844 & 11.31645 \\
\hline
\end{tabular}
locations having rainfall data for a 30-year mean for each month during the period of $1931 \sim 1964$. The name of each location and its coordinates are shown in Table 2 and Fig 2, respectively.

Table 2. Named locations (LOC) for historical data. 
Table 3. Historical rainfall data for the period of $1931 \sim 1964$.

\begin{tabular}{|c|c|c|c|c|c|c|c|c|c|c|c|c|}
\hline \multirow{2}{*}{ LOC } & \multicolumn{12}{|c|}{ Rainfall (mm/month) } \\
\hline & Jan & Feb & Mar & Apr & May & Jun & Jul & Aug & Sep & Oct & Nov & Dec \\
\hline 1 & 83.8 & 75.2 & 43.7 & 68.6 & 121.4 & 217.2 & 201.4 & 207.3 & 159.5 & 191.8 & 208.3 & 175.3 \\
\hline 2 & 148.8 & 112.5 & 76.2 & 121.4 & 265.7 & 412.8 & 382.0 & 342.1 & 263.1 & 296.7 & 322.3 & 297.2 \\
\hline 3 & 85.1 & 94.2 & 37.6 & 76.2 & 160.5 & 340.6 & 301.2 & 274.8 & 198.4 & 209.0 & 229.1 & 191.0 \\
\hline 4 & 162.6 & 104.6 & 88.6 & 119.6 & 200.4 & 335.0 & 310.9 & 337.6 & 230.6 & 272.8 & 332.5 & 317.0 \\
\hline 5 & 95.5 & 70.4 & 53.6 & 60.5 & 110.7 & 201.9 & 252.0 & 281.7 & 214.6 & 192.3 & 184.2 & 166.1 \\
\hline 6 & 139.2 & 116.6 & 77.5 & 55.9 & 84.3 & 216.4 & 269.2 & 333.2 & 232.7 & 164.8 & 190.0 & 180.3 \\
\hline 7 & 64.0 & 44.7 & 44.2 & 61.5 & 99.8 & 187.2 & 206.2 & 252.0 & 205.7 & 172.5 & 192.5 & 138.9 \\
\hline 8 & 68.1 & 39.6 & 33.0 & 49.0 & 53.3 & 224.0 & 218.4 & 244.9 & 182.1 & 162.8 & 190.5 & 158.2 \\
\hline 9 & 72.6 & 42.4 & 34.5 & 55.9 & 132.8 & 239.8 & 226.8 & 246.9 & 174.8 & 157.5 & 195.8 & 168.9 \\
\hline 10 & 64.3 & 40.5 & 24.0 & 34.5 & 68.2 & 160.6 & 187.0 & 218.2 & 162.5 & 140.0 & 166.3 & 138.9 \\
\hline 11 & 113.9 & 69.9 & 40.2 & 51.5 & 127.4 & 308.8 & 316.1 & 258.9 & 202.9 & 212.8 & 255.8 & 215.8 \\
\hline 12 & 157.5 & 93.1 & 83.2 & 96.2 & 169.9 & 307.1 & 316.2 & 282.3 & 244.5 & 265.1 & 338.8 & 335.3 \\
\hline 13 & 93.0 & 64.8 & 43.1 & 55.7 & 97.3 & 252.3 & 241.2 & 260.4 & 213.7 & 185.4 & 219.1 & 180.3 \\
\hline 14 & 130.0 & 70.1 & 60.2 & 74.4 & 140.7 & 246.1 & 204.5 & 231.9 & 159.0 & 172.7 & 229.9 & 233.7 \\
\hline 15 & 156.2 & 82.6 & 62.0 & 100.6 & 152.7 & 264.2 & 231.6 & 247.9 & 169.9 & 191.5 & 258.6 & 286.3 \\
\hline 16 & 102.6 & 55.6 & 45.0 & 58.7 & 135.6 & 233.7 & 202.4 & 189.5 & 142.7 & 160.5 & 203.2 & 228.1 \\
\hline 17 & 94.2 & 61.2 & 45.0 & 62.0 & 127.3 & 224.0 & 222.3 & 241.8 & 158.2 & 154.4 & 176.3 & 156.7 \\
\hline 18 & 87.6 & 64.8 & 50.5 & 57.4 & 92.7 & 215.1 & 177.8 & 222.5 & 145.3 & 139.7 & 166.4 & 148.8 \\
\hline 19 & 81.0 & 85.1 & 66.3 & 79.2 & 105.2 & 240.3 & 228.1 & 281.2 & 182.6 & 172.2 & 189.5 & 170.7 \\
\hline 20 & 110.2 & 68.3 & 63.2 & 67.6 & 83.1 & 182.1 & 194.8 & 159.3 & 113.0 & 104.1 & 152.4 & 146.8 \\
\hline 21 & 57.7 & 60.5 & 37.6 & 49.0 & 74.4 & 182.4 & 173.0 & 183.4 & 125.5 & 176.5 & 175.3 & 145.8 \\
\hline 22 & 60.2 & 54.1 & 34.0 & 54.6 & 110.0 & 172.2 & 199.4 & 197.9 & 172.2 & 163.3 & 210.6 & 178.3 \\
\hline 23 & 96.3 & 72.1 & 43.4 & 69.1 & 146.3 & 223.5 & 239.3 & 210.6 & 197.1 & 192.0 & 254.5 & 200.7 \\
\hline 24 & 103.9 & 80.5 & 54.1 & 50.0 & 112.3 & 173.2 & 195.8 & 215.9 & 200.9 & 240.8 & 227.1 & 173.5 \\
\hline 25 & 102.1 & 102.1 & 48.5 & 77.0 & 118.4 & 204.5 & 236.5 & 216.7 & 197.4 & 303.5 & 266.4 & 190.8 \\
\hline 26 & 205.0 & 147.8 & 94.7 & 100.6 & 170.2 & 328.4 & 312.9 & 251.7 & 283.2 & 325.4 & 331.2 & 283.2 \\
\hline 27 & 129.3 & 85.1 & 52.6 & 79.5 & 146.8 & 213.6 & 226.8 & 188.7 & 212.6 & 201.9 & 280.9 & 232.7 \\
\hline 28 & 154.9 & 90.2 & 66.3 & 87.6 & 163.8 & 255.8 & 253.0 & 233.7 & 256.3 & 235.7 & 326.6 & 264.9 \\
\hline
\end{tabular}

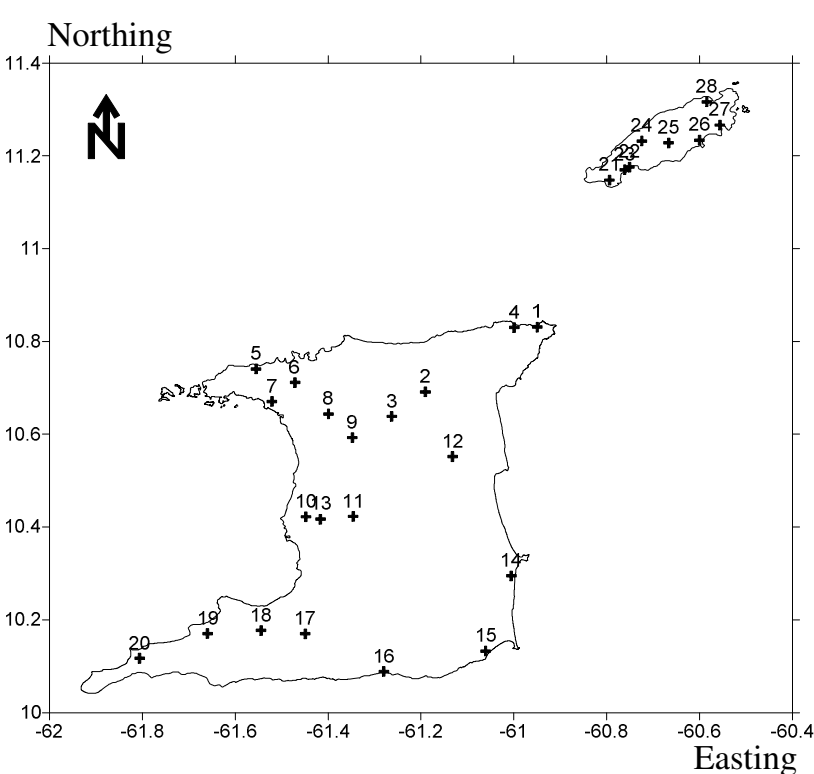

Fig. 2. Locations of historical rainfall data in Trinidad and Tobago.

\subsection{Climate data}

\subsubsection{Rainfall}

The historical rainfall data at the 28 locations are given in Table 3. Locations (LOC) 1-9 are from the northern part of Trinidad, LOC 10-13 are from the central part of Trinidad, and LOC 14-20 are from the southern part of Trinidad. LOC 21-28 are from Tobago. The spatial distribution of the locations would help in the interpolation accuracy of the TMI map. Table 4 gives the mean monthly rainfall at the MET office location, Piarco, for a recent period of $1981 \sim 2018$ [16]. This set of data is compared with historical data, for the LOC 9 (Piarco), to investigate the coherence and reliability of using the historical data.

\subsubsection{Temperature}

The mean monthly temperature is also given in Table 4 from the Met Office for the period of $1981 \sim 2018$ [16]. It is assumed that these monthly temperature readings are the same throughout Trinidad and Tobago. The temperature data shows a suitable increase in 
temperatures during May and August but has an overall similar mean temperature throughout the year.

Table 4. Mean monthly rainfall and temperature at the Met Office, Piarco, for the period of $1981 \sim 2018$.

\begin{tabular}{|c|c|c|}
\hline Month & Rainfall (mm) & Temperature $\left({ }^{\mathbf{0}} \mathbf{C}\right)$ \\
\hline Jan & 72.5 & 26.27 \\
\hline Feb & 38.2 & 26.89 \\
\hline Mar & 26.9 & 27.39 \\
\hline Apr & 30.4 & 28.14 \\
\hline May & 105.2 & 28.21 \\
\hline Jun & 245.4 & 27.59 \\
\hline Jul & 229.5 & 28.13 \\
\hline Aug & 233.9 & 28.22 \\
\hline Sep & 177.12 & 27.93 \\
\hline Oct & 208.8 & 27.71 \\
\hline Nov & 232.8 & 27.04 \\
\hline Dec & 156.9 & 26.52 \\
\hline
\end{tabular}

\subsection{Spatial distribution of TMI}

Surfer is a GIS software, used to visualise and analyse data at known locations or points quickly, and can further interpolate data where they do not exist within a specified region. Data processing in Surfer allows for 2D and 3D map generation from the spatial distribution of data.

Calculated TMI values with known coordinates are imported into the GIS Software Surfer from an excel data file. The kriging interpolation method is chosen as the preferred gridding method to generate the spatial distribution of TMI data within the regions of Trinidad and Tobago shown in Fig. 2. The processed data in Surfer is further visualised into blue coloured contours with increments of five TMI. The contours are darker for highly positive values and get extremely light towards the lower values of the TMI.

\section{Results and discussion}

Fig. 3 shows the comparison of both rainfall distributions for the historical data set and present at the Piarco location. The present set of continuous data is only at one location and cannot be used to examine the TMI throughout Trinidad and Tobago spatially. In order to statistically examine the reliability and coherence of the historical data to the present data at the Piarco location, a t-test (Paired Two Sample for Means) was carried out using the Data Analysis toolbox in Microsoft Excel (2016) [18]. The t-test examined the null hypothesis; there is no statistically significant difference between the mean rainfall data between the selected time periods of (1981-2018) and (1931-1961) at the Piarco Location. The t-test gives a p-value of 0.913 , which is greater than the set alpha (significance) level of 0.05 , and the t-value of 0.111 , which is less than the t-critical $=2.2$ for a two-tail analysis. The results of the $\mathrm{p}$-value and $\mathrm{t}$-value from the $\mathrm{t}$-test indicates that the null hypothesis is accepted and cannot be rejected. Also from the t-test, a pearson correlation value of 0.967 was obtained an indicates a strong correlation in comparing both data sets.

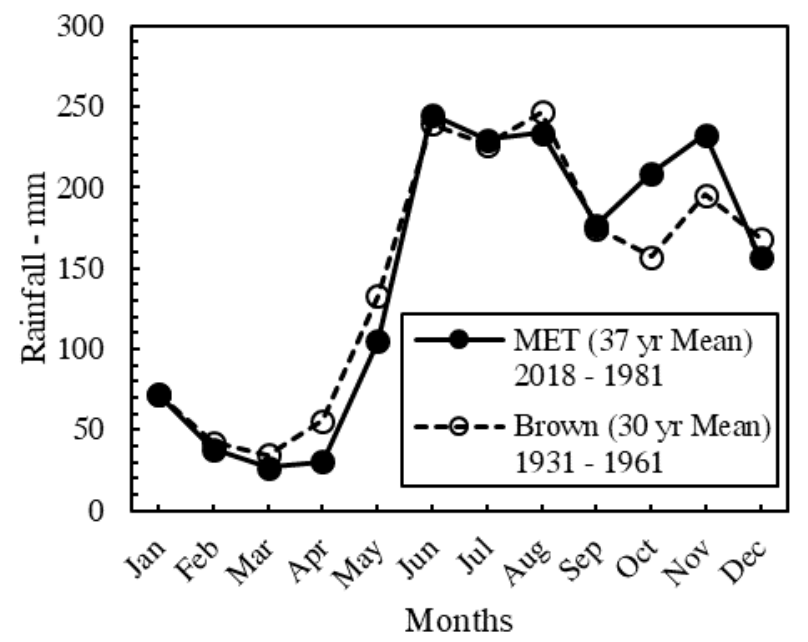

Fig. 3. Comparison of monthly rainfall data sets at Piarco.

Table 5. Calculated TMI values at each location.

\begin{tabular}{|c|c|c|c|c|c|c|}
\hline LOC & $\begin{array}{c}\text { Yearly } \\
\text { Deficits } \\
\text { (mm) }\end{array}$ & $\begin{array}{c}\text { Yearly } \\
\text { Surplus } \\
(\mathbf{m m})\end{array}$ & $\begin{array}{c}\mathbf{P E} \\
(\mathbf{m m})\end{array}$ & $\mathbf{I}_{\mathbf{a}}$ & $\mathbf{I}_{\mathbf{h}}$ & TMI \\
\hline 1 & -267 & 225 & 1874 & 14 & 12 & 3 \\
\hline 2 & -42 & 1077 & 1873 & 2 & 57 & 56 \\
\hline 3 & -206 & 530 & 1873 & 11 & 28 & 22 \\
\hline 4 & -39 & 988 & 1874 & 2 & 53 & 52 \\
\hline 5 & -269 & 369 & 1873 & 14 & 20 & 11 \\
\hline 6 & -200 & 446 & 1873 & 11 & 24 & 17 \\
\hline 7 & -345 & 221 & 1873 & 18 & 12 & 1 \\
\hline 8 & -416 & 205 & 1873 & 22 & 11 & -2 \\
\hline 9 & -321 & 221 & 1873 & 17 & 12 & 1 \\
\hline 10 & -468 & 84 & 1873 & 25 & 5 & -10 \\
\hline 11 & -256 & 557 & 1873 & 14 & 30 & 22 \\
\hline 12 & -92 & 908 & 1873 & 5 & 48 & 46 \\
\hline 13 & -305 & 389 & 1873 & 16 & 21 & 11 \\
\hline 14 & -188 & 360 & 1873 & 10 & 19 & 13 \\
\hline 15 & -136 & 467 & 1873 & 7 & 25 & 21 \\
\hline 16 & -262 & 224 & 1873 & 14 & 12 & 4 \\
\hline 17 & -270 & 203 & 1873 & 14 & 11 & 2 \\
\hline 18 & -306 & 142 & 1873 & 16 & 8 & -2 \\
\hline 19 & -242 & 326 & 1873 & 13 & 17 & 10 \\
\hline 20 & -428 & 68 & 1873 & 23 & 4 & -10 \\
\hline 21 & -433 & 96 & 1874 & 23 & 5 & -9 \\
\hline 22 & -347 & 152 & 1874 & 19 & 8 & -3 \\
\hline 23 & -233 & 386 & 1874 & 12 & 21 & 13 \\
\hline 24 & -259 & 237 & 1874 & 14 & 13 & 4 \\
\hline 25 & -212 & 470 & 1874 & 11 & 25 & 18 \\
\hline 26 & -44 & 1004 & 1874 & 2 & 54 & 52 \\
\hline 27 & -171 & 445 & 1874 & 9 & 24 & 18 \\
\hline
\end{tabular}




\section{Northing}

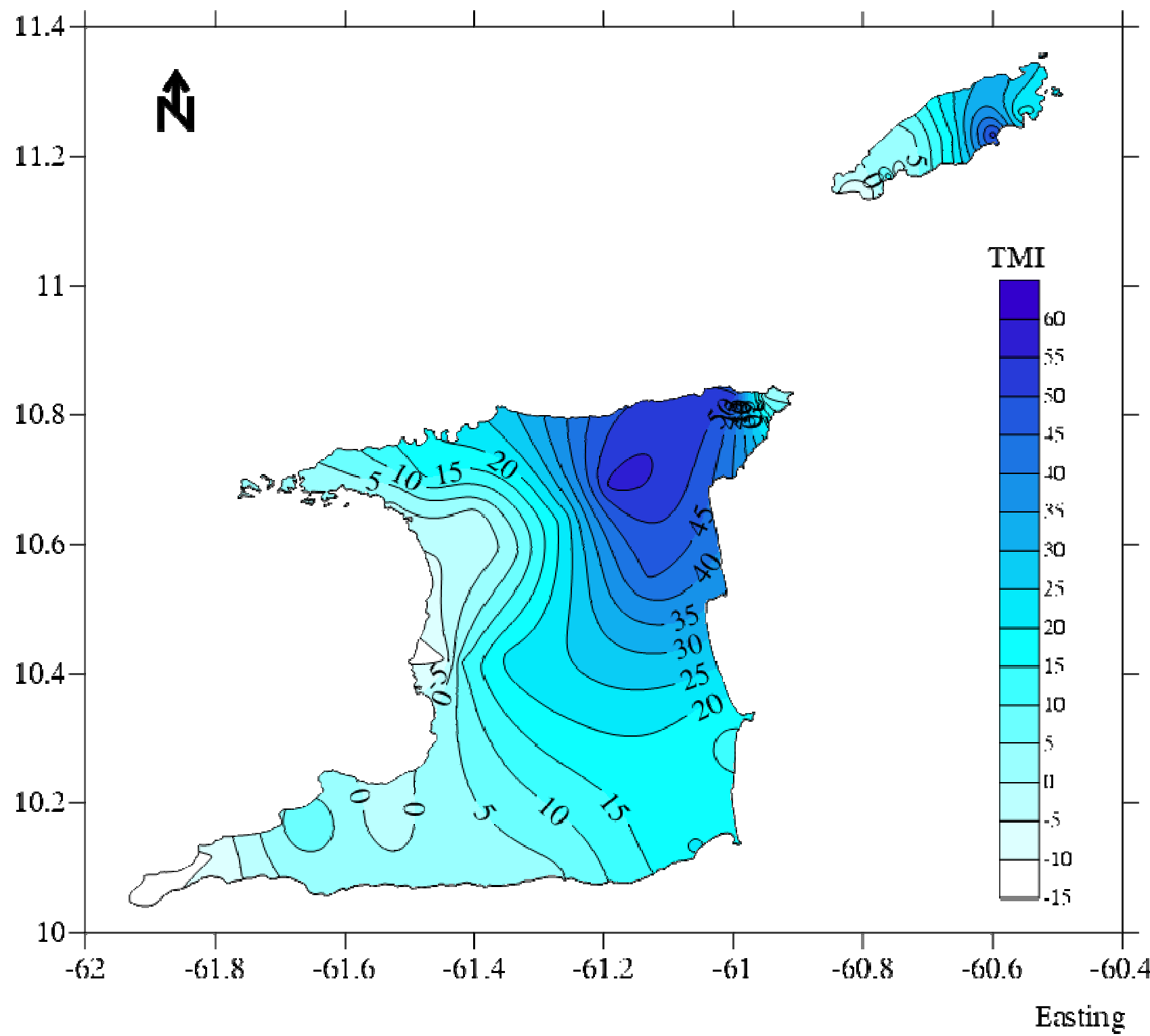

Fig. 4. Proposed TMI map of Trinidad and Tobago

The monthly temperature data at the historic locations are not given, only its average of $26.2^{\circ} \mathrm{C}$ recorded. Having a high coherence of the rainfall data, it is also assumed that the mean monthly temperature at the Piarco location presently can be used for the determination of PE for all locations.

Calculated TMI values are given in Table 5 using Equations 1-4. Fig. 4 shows the TMI map created using Surfer [17]. The highest value of TMI in the northeastern side of Trinidad indicates a minimal amount of moisture variations within soils in this region. Coincidentally, in the north-eastern area of Trinidad, one of its largest dams named the Hollis Reservoir is located. The Hollis Reservoir location was most likely selected based on the high record of yearly rainfall. Moving to the southern part of Trinidad, the TMI values decrease towards the south-western tip.

At the central part of Trinidad, on the western side of the island, there is also significantly low TMI values.
These low TMI values indicate that, within the western side of the island, moisture variations can be substantial from longer dry seasons. Expansive clays in these areas would be prone to significant volume change and affect shallow foundations resting on them. In Tobago, at both ends on the island, the TMI values are low and a bit higher nearer to its center. Although moisture variations can be high, the soils in this island are generally nonexpansive.

\section{Conclusion}

A TMI map has been developed using the historical data for the period of $1931 \sim 1964$. It was observed that, for the Piarco location, the mean rainfall data for the period of $1931 \sim 1964$ are similar to the mean values for the period of $1981 \sim 2018$. Areas in Trinidad are highlighted where moisture variations are high. This map can be

Corresponding author: damian.alexander@my.uwi.edu 
used to assist engineers for foundation designs on expansive clays and can be further developed with the availability of spatial data.

\section{References}

1. C.W. Thornwaite, Geographical Review, 38, 55-94 (1948)

2. A. Grundstein, Climatic Change, 93 (2009)

3. S. Leao, N.Y. Osman-Schlegel, 7th Australasian Housing Researchers' Conference (2014)

4. A. Michael, P. Taylor, M.L. Philp, Int. J. Sustainable Transportation, 10, 528-540 (2016)

5. A. Zareie, S.R. Amin, L.E. Amador-jiménez, J. Transportation Eng., 142, 1-11 (2016)

6. K. Russam, D. Coleman, Géotechnique, 11, 22-28 (1961)

7. S.G. Fityus, O. Buzzi, Australian Geomechanics, 43, 69-76 (2008)

8. Uniform building code, Int. Conf. Bldg. Officials. (1997)

9. Australian Standard, AS2870-2011 (2011)

10. K.N. Venkataramana, West Indies J. Eng., 25, 1 (2002)

11. K.V. Ramana, West Indies J. Eng., 18, 1 (1995)

12. B.C. Brown, J.F.R. Hansell, I.D. Hill, I. Stark, G.W. Smith, Land capability survey of Trinidad and Tobago. No. 1. Tobago (1965)

13. B.C. Brown, Land capability survey of Trinidad and Tobago. No. 3, soils of the northern range Trinidad (1966)

14. B.C. Brown, Land capability survey of Trinidad and Tobago. No. 4, soils of central Trinidad (1970)

15. B.C. Brown, G.S. Bally, Land capability survey of Trinidad and Tobago. No. 5, soils of south Trinidad (1986)

16. Trinidad and Tobago Meteorological Service, Mean Rainfall and Temperature (2018)

17. Golden Software, SURFER Ver. 12

18. Microsoft Excel Software, Data Analysis Toolbar (2016) 